\title{
Preliminary Study on the Gender Differences in the Online Shopping of College Students
}

\author{
Danwen Chen \\ School of Education \\ Jianghan University \\ Wuhan, China
}

\author{
Xuan Luo \\ School of Education \\ Jianghan University \\ Wuhan, China
}

\begin{abstract}
Under the background of the Internet Plus, the literature review method, questionnaire method and integrated data analysis method are applied in the research to analyze the differences between the male and female college students in the consuming behavior of online shopping and the decision-making factors. The specific research method is as follows: The questionnaires are distributed through WJX.cn. A total of 162 valid questionnaires are collected. The respondents are college students, including 79 male college students and 83 female college students. The scales include the Questionnaire on the Preference of College Students in Online Shopping compiled by Wang Zhiwen in 2013, and the Questionnaire on the Decisionmaking Style of College Students in Online Shopping compiled by Liu Jun in 2009. The investigation result shows: Male and female college students have big differences in the kind of online shopping, the available amount of online shopping, the total consumption of online shopping and the decision making of online shopping. The SPSS20.0 is used to conduct the variance analysis on the data in the decision making of online shopping, and the result shows: Male and female college students have different selection preference in the online shopping. In the online shopping, the scores of female college students are higher than that of the male college students in five dimensions, including the confusion of decision making, novelty and fashion, recommendation and reference, entertainment and careful calculation and strict budgeting. However, the score of male college students is higher than that of the female college students in paying attention to the dimension of brand. The research aims at providing guidance for the college students to establish the correct consumption view of online shopping as well as providing some helps for the electronic commerce enterprises in some operating strategies.
\end{abstract}

Keywords-college students; gender; online shopping; difference

\section{INTRODUCTION}

The popularization of the network makes people's life change with each passing day. The electronic commerce is being accepted by the majority of people. One of the characteristics of college students is that they are quick in embracing new things. They are the mainstream group and core force in the new pattern of the online shopping consumption at present. College students, the special group, is investigated in this research, especially the gender differences in the kind of online shopping needs and the gender differences in the decision making of online shopping, in order to provide guidance for different groups to establish the correct consumption view on the online shopping, at the same time providing some helps for electronic commerce enterprises in marketing strategies.

\section{RESEARCH METHODS}

\section{A. Research Ideas}

From the respective of gender difference, the research explores the characteristics of college students in the network consumption behavior and the decision-making style. The SPSS20.0 is used to conduct the variance analysis on the data in the aspect of decision making in online shopping. Finally, the related conclusion is reached.

The basis of the research is the paper of Li Jun, the Compilation of the Questionnaires on the Decision-making Style of College Students in Online Shopping and the Actual Measurement. The open questionnaire survey is conducted on college students. According to the structure arrangement and classification of questionnaire, the decision-making style of college students in the online shopping includes: the confusion of decision making, valuing reputation, novelty and fashion, recommendation and reference, entertainment, careful calculation and strict budgeting, paying attention to the dimension of brand.

\section{B. Research Tools}

The questionnaires are the Questionnaire on the Preference of College Students in Online Shopping compiled by Wang Zhiwen in 2013, and the Questionnaire on the Decisionmaking Style of College Students in Online Shopping compiled by Liu Jun in 2009.

\section{Research Objects}

The college students are research objects. The questionnaires are distributed through the network questionnaire platform of "Wenjuanxing". A total of 195 questionnaires are collected, including 162 valid questionnaires, with the effective rate of $83.08 \%$. The numbers of valid questionnaires contributed by male and female college students are 79 and 83 respectively. 


\section{DATA ANALYSIS}

\section{A. The Demographic Characteristic of the Sample}

As shown in the following "Table I", in the survey, there are 162 college students participate in the online shopping, including 79 male college students and 83 female college students, occupying $48.8 \%$ and $51.2 \%$ respectively. The figure shows the online shopping is very popular among college students, and the difference of proportion of male and female college students in the online shopping is not big.

TABLE I. GENDER CHARACTERISTICS

\begin{tabular}{|l|l|l|}
\hline \multicolumn{1}{|c|}{ Gender } & \multicolumn{1}{c|}{ Total } & Proportion \\
\hline Male & 79 & $48.8 \%$ \\
\hline Female & 83 & $51.2 \%$ \\
\hline Total & 162 & $100 \%$ \\
\hline
\end{tabular}

B. The Influence of Gender Difference on the Kind of Online Shopping

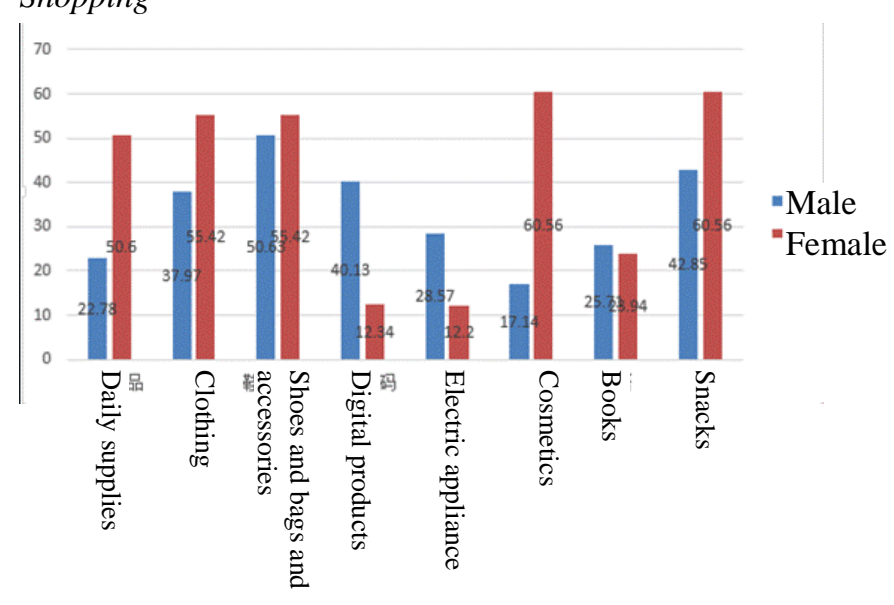

Fig. 1. The influence of gender difference on the kind of online shopping.

According to "Fig. 1", both male and female college students purchase many clothes, shoes and hats and accessories as well as snacks. It may be related to the requirements of college students. The proportion of male college students is higher than female college students in purchasing electronic digital products. However, the proportion of male college students is higher than male college students in purchasing cosmetics and daily supplies. It is caused by the living needs of male and female college students.

The investigation also shows the college students of different genders have different inclination on the products purchased during the online shopping festivals. Female college students pay more attention to the products like clothes, shoes and bags, cosmetics and snacks. It shows male and female college students have different preference in shopping in the online shopping festivals in "Table II".

\section{The Influence of Gender Difference on the Available Amount in Online Shopping}

TABLE II. THE INFLUENCE OF GENDER DIFFERENCE ON THE AVAILABLE AMOUNT IN ONLINE SHOPPING

\begin{tabular}{|l|l|l|l|}
\hline & \multicolumn{1}{|c|}{ Male } & Female & Total \\
\hline Below 300 yuan & 27 & 9 & 36 \\
\hline 300-500 yuan & 9 & 26 & 35 \\
\hline 500-1000 yuan & 23 & 29 & 52 \\
\hline Above 1000 yuan & 20 & 19 & 39 \\
\hline Total & 79 & 83 & 162 \\
\hline
\end{tabular}

D. The Influence of Gender Difference on the Total Consumption of Online Shopping

TABLE III. THE INFLUENCE OF GENDER DIFFERENCE ON THE TOTAL CONSUMPTION OF ONLINE SHOPPING

\begin{tabular}{|l|l|l|l|}
\hline & Male & Female & Total \\
\hline Below 100 yuan & 9 & 2 & 11 \\
\hline 100-300 yuan & 26 & 19 & 45 \\
\hline 301-500 yuan & 19 & 25 & 44 \\
\hline 500-1000 yuan & 16 & 21 & 37 \\
\hline Above 1000 yuan & 9 & 16 & 25 \\
\hline Total & 79 & 83 & 162 \\
\hline
\end{tabular}

According to the investigation report on the sum of consumption of online shopping of college students, the available amount of college students in online shopping is closely related to the total consumption of online shopping. The higher the available amount, the higher the sum of consumption in online shopping will be. The table of available amount shows the available amount of female college students is higher than that of the male college students. On one hand, female college students have more conscious in saving money and distributing money in daily life. Therefore, the available amount of female college students in online shopping is higher than that of the male college students; on the other hand, it may be related to the family education pattern in our country. People in our country believe "we must raise a son by giving him a little money, while a daughter by giving her lots of money". Therefore, parents will be different in giving living expenses to their children, and the available amount of female college students is higher than that of male college students. During the online shopping festival, the male college students with the total consumption between 100 and 300 yuan, 300 and 500 yuan, 500 to 1000 yuan are in the majority. However, the female college students with the total consumption between 300 and 500 yuan, 500 and 1000 yuan and above 1000 yuan are in the majority in "Table III".

\section{E. The Influence of Gender Difference on the Decision Making of Online Shopping}

In this analysis, the independent variable is gender, and the dependent variables are the confusion of decision making, valuing reputation, novelty and fashion, recommendation and reference, entertainment, careful calculation and strict budgeting, paying attention to the dimension of brand. The result through variance analysis shows among the seven variables, only the variance analysis of "valuing reputation" and "novelty and fashion" fails to reach the significant, and the differences of other five dependent variables on gender reach the significant. Specifically, the female college students pay 
more attention to the five dimension of "the confusion of decision making", "novelty and fashion", "recommendation and reference", "entertainment" and "careful calculation and strict budgeting" than male college students; more male college students "pay attention to the dimension of brand" than female college students. The detail is shown in "Table IV".

TABLE IV. SUMMARY TABLE OF THE VARIANCE ANALYSIS OF GENDER ON THE DECISION-MAKING STYLE OF ONLINE SHOPPING CONSUMPTION

\begin{tabular}{|l|l|l|}
\hline \multicolumn{1}{|c|}{ Variable } & \multicolumn{1}{|c|}{ F } & Posterior comparison \\
\hline $\begin{array}{l}\text { The confusion of decision } \\
\text { making }\end{array}$ & $4.142^{* *}$ & Female $>$ male \\
\hline Valuing reputation & .399 & \\
\hline Novelty and fashion & 0.132 & Female $>$ male \\
\hline Recommendation and reference & $9.971^{* *}$ & Female $>$ male \\
\hline Entertainment & $0.344 * *$ & Female $>$ male \\
\hline $\begin{array}{l}\text { Careful calculation and strict } \\
\text { budgeting }\end{array}$ & $8.297^{* *}$ & Female $>$ male \\
\hline Valuing brand & $7.261 * *$ & Male $>$ Female \\
\hline
\end{tabular}

According to the variance analysis, in the decision making process of shopping online, the gender difference will influence the decision making in shopping. On the dimensions of the confusion of decision making, novelty and fashion, recommendation and reference, entertainment and careful calculation and strict budgeting, the scores of female college students are significantly higher than that of the male college students, while male college students obtain a significantly higher score than female students in the dimension of paying attention to brand. It shows female college students are more willing to treat online shopping as a way of relaxing, and become confused and helpless in facing the tremendous information of goods and then seek help from others. Male college students are saner and more independent in online shopping. In online shopping, female college students pay more attention to the expense of goods, while male college students are inclined to choose the famous brand. The characteristics of shopping online are similar to the characteristics of male and female college students in shopping in the real life.

\section{DISCUSSION}

\section{A. Discussion on the Reason for the Preference Difference of Male and Female College Students in Online Shopping}

The difference is analyzed through comparing the shopping inclination of male and female college students in the sort of goods in online shopping:

The difference between male and female college students in choosing the goods in online shopping is because male and female college students have different living needs. During the carnival of online shopping, the goods purchased by male and female college students have a big difference:

Compared with male college students, female college students prefer to purchase clothes, cosmetics and daily supplies online during the shopping spree. On one hand, compared with the male college students, female college students have stronger mentality of pursuing beauty. Therefore, during the carnival of online shopping, female college students will purchase more clothes and cosmetics that embody their sense of fashion and catch others' eyes or get the praise. The praise of others will further stimulate the desire of female college students in purchasing. On the other hand, the shopping spree is during the period of changing dress proper for the season, so compared with the male, female college students are more inclined to seek fashion. In shopping spree, female college students will purchase the clothes that conform to the current trend to meet their demands for fashion trend. Female college students have a higher impulsion in purchasing clothes and cosmetics than male college students. Since female college students have the consumption concept that they pay more attention to the appearance and the appropriateness of the clothes and cosmetics except for its use, they will have the impulse of consumption of these goods in online shopping.

Compared with the female college students, the male college students are more inclined to purchase digital electronic goods and electric appliance online in the carnival of online shopping; male college students are more interested in products of science and technology than female college students, who have a lower interest in high technology than the male. Female college students prefer the simple electronic products, while male college students prefer to research hightech products and accept high-tech products more easily.

No significant difference between male and female college students in books, shoes, bags and accessories in the carnival of online shopping exists. Their shopping inclination on these things is almost the same. According to the above analysis, we can see in the carnival of online shopping, the gender difference of male and female college students will lead to the different preference of online shopping. The big difference appears.

\section{B. Discussion on the Reasons for the Difference of the Consumption Level of Male and Female College Students in Online Shopping}

The comparison of the available amount and the sum of consumption of male and female college students in the carnival of online shopping shows, the available amount of college students in online shopping is closely linked to the total consumption of online shopping. The higher the available amount, the higher the sum of consumption of online shopping will be.

The reasons why female college students have a higher available amount than male college students are as follows: On one hand, the saving consciousness of female college students is higher than that of the male college students. Female college students are more conscious in distributing money in daily life. They have a higher ability in calculating the expense in daily life and control their daily expense. However, male college students often lack the consciousness of distributing the money in life and will not consider whether it exceeds their budget in spending money. Female college students will save money at ordinary times, contributing to the higher available amount of female college students than male college students in online shopping; on the other hand, it may be connected to the family education pattern in our country. The traditional educational concept believes "we must raise a son by giving him a little 
money, while a daughter by giving her lots of money", in order to guide the children's attitudes towards money. Therefore, parents will be different in giving living expenses to children, leading to the higher available amount of female college students than male college students.

Female college students belong to sensibility consumption in online consumption. They will purchase their favorable products when their available amount is high. In purchasing goods, female college students seldom consider whether they have alternatives for the goods. For example, female college students will corner in some cosmetics and articles of daily use, instead of purchasing them whey they must be replaced. Besides, female college students have more careful calculation and strict budgeting than male college students in purchasing. The products during the carnival of online shopping are greatly cheaper than usual, so female college students will purchase many price-off products in the carnival of online shopping. Some even choose some products before the carnival of online shopping and put them in the shopping trolley, and purchase them when the price is off in the carnival, in order to reduce the expense. Therefore, the investigation report shows the female spend more money in the shopping spree and the proportion of the female in the high consumption in online shopping is higher than the male. In the online shopping, male college students are inclined to rational consumption. They will purchase the products required by them and will not browse other products after purchasing the required products. Therefore, male college students purchase less products online, with a low sum of consumption.

\section{Discussion on the Influence Factors of Decision Making for Male and Female College Students in Online Shopping}

According to the result of the questionnaire, the scores of female college students are higher than that of the male college students in the five dimensions of the confusion of decision making, novelty and fashion, recommendation and reference, entertainment and careful calculation and strict budgeting in online shopping, while male college students obtain a significantly higher score than female college students in the dimension of valuing the brand. This shows in the carnival of online shopping, the female college students are more willing to treat the online shopping as a way of relaxing, and become confused and helpless in facing the tremendous information of goods, and then turn to others for help. Female college students are more rational and independent in online shopping. In online shopping, female college students pay attention to the expense of goods, while male college students are inclined to choose the famous brands. Male college students choose rational consumption in online shopping, so they will often consider the quality of goods. Therefore, male college students will attach importance to brands in online shopping, preferring the famous brands. However, female college students are more willing to treat the online shopping in carnival as a way of relaxing, closer to the realistic consumption. Furthermore, female college students are more likely to pursue fashion and trend, so they prefer to refer to others' recommendation and choose the fashionable goods. Female college students will inquire the opinions of others in purchasing because they have more confusions in choosing goods and need the support of others; on the other hand, female college students attach more importance to the price of goods in the consumption of online shopping, so they are more willing to purchase the goods required recently on the carnival of online shopping. Therefore, female college students have more careful calculation and strict budgeting than male college students.

\section{CONCLUSION}

The proportions of male and female college students that participate in the carnival of online shopping are almost the same. It shows among college students, the gender difference does not have a great influence on the participation of college students in online shopping.

In the carnival of online shopping, the gender difference causes different shopping preference. Female college students prefer to purchase clothes, cosmetics and daily supplies online during the carnival of shopping spree; while male college students prefer to purchase digital electronic products and electric appliance in the carnival of online shopping; no obvious difference between male and female college students in the carnival of online shopping exists in purchasing books, shoes, bags and accessories.

The available amount and the sum of consumption of college students are different in the carnival of online shopping. Generally speaking, the available amount and the sum of consumption of female college students are higher than that of the male college students. Male college students are inclined to rational consumption while female college students tend to sensibility consumption.

The gender difference influences the decision making factor of online shopping. The scores of female college students on the five dimensions of the confusion of decision making, novelty and fashion, recommendation and reference, entertainment and careful calculation and strict budgeting are higher while the score of male college students is higher on the dimension of valuing the brand. The gender difference is not significant on the dimensions of novelty and fashion and valuing reputation.

\section{REFERENCES}

[1] Xie Shilong. Investigation on the Online Shopping Behavior of the College Students [J], Manager's Journal, 2015(34):339-340.

[2] Fu Huaqi. Research on the Online Shopping Situation of College Students Based on the Questionnaire Survey [J], Scientific Consultation: Technology and Management, 2016 (4):22-23.

[3] Bai Pengfei. Research on the Online Shopping Behavior of College Students [J], CO-Oerativeconomy and Science, 2015(7):104-106.

[4] Hu Liqin, Shi Fangyu. Investigation and Research on the Online Shopping Behavior of College Students [J], Global Market Information Guide, 2015 (4):111-111.

[5] Bai Zehong, Geng Mengxue, Fang Yong. Investigation and Analysis on the Online Shopping Situation of College Students [J], China Collective Economy, 2016 (13):24-25

[6] Zhao Jie, Liu Zhen. Analysis on the Psychology of College Students in Online Shopping and the Online Marketing Strategy [J], Industrial and Science Tribune, 2014.13 (2):106-106.

[7] Wang Zhiwen. Investigation Report on the Preference of College Students in Online Shopping [A], University of International Business and Economics, 2013. 
[8] Sheng Xiaojun, Yuan Xuhui, Chen Meidai. Discussion on the Influence Factors of the Online Shopping of College Students and the Gender Differences [J], Contemporary Economics, 2016 (9):121-124.

[9] Zhang Shushu, Zhang Zhiguang. The Gender Differences in Online Shopping Behavior and Network Marketing Strategy [J], Journal of Nanjing Forestry University (Humanities and Social Sciences Edition, 2012 .12 (2): 94-99.

[10] Jiang Huan, Zhou Faming. Research on the Gender Difference on the Factors Influencing the Inclination of Online Shopping [J], Technological Development of Enterprise: Academic Edition, 2010.29 (7):90-91.

[11] Chen Ke. The Influence of Product Types on the Gender Differences of Online Preference [J], Market Modernization, 2007 (5):163-164.

[12] Wu Sai, Qi Zhenbiao, Gao Jingguang. Empirical Research on the Gender Factors Influencing the Decision Making of College Students in Online Shopping [J], Management and Technology of SME (Periodical Appearing Once Every Ten Days), 2013 (18):150-151.

[13] Wang Fuwei, Fu Mianping. Analysis on College Students' Online Purchase Process $[\mathrm{J}]$. Journal of Heilongjiang Foreign Economic and Trade convention, 2011,199 (1): P62-63.

[14] Moez Limayem, Mohamed Khalifa, and Anissa Frini. "What Makes Consumers Buy from Internet? A Longitudinal Study of Online Shopping". "Systems Man \& Cybernetics Part A Systems \& Humans IEEE Transactions on".2000, 30 (4): 421 - 432.

[15] Liu Jun. The Compilation of the Questionnaires on the Decision-making Style of College Students in Online Shopping and the Actual Measurement [A], Southwest University, 2009. 